\title{
La Revista en internet y más allá
}

En esta ocasión les quiero compartir algunos datos que muestran cuál es la visibilidad de la Revista Colombiana de Radiología.

Como órgano oficial de difusión científica de la Asociación Colombiana de Radiología y una de sus principales publicaciones, se puede acceder libremente a sus artículos en este vínculo: http://www.acronline.org/Publicaciones/Revista-Colombiana-de-Radiolog\%C3\%ADa

Recordemos que desde 2017 todos los artículos están disponibles no solo en español, sino también en inglés.

Desde hace diez años, la Revista Colombiana de Radiología ha participado con dos artículos en cada uno de los números trimestrales de la revista virtual del Colegio Interamericano de Radiología (CIR), en la cual los artículos están publicados en español y en inglés. Esta importante publicación reúne también artículos de las siguientes publicaciones:

»Radiología (de la Sociedad Española de Radiología)

»Revista Argentina de Radiología

» Radiologia Brasileira

» Acta Radiológica Portuguesa

» Revista Chilena de Radiología

"Anales de Radiología de México

» Revista Imagenología de la Sociedad de Radiología e Imagenología del Uruguay

» Revista de la Federación Ecuatoriana de Radiología

» RadioGraphics (de la Radiological Society of North America [RSNA])

» Radiology (también de la RSNA). El vínculo a la revista virtual del CIR es: http://www.webcir.org/revistavirtual/

La Revista Colombiana de Radiología está en el índice Literatura Latinoamericana y del Caribe en Ciencias de la Salud (LILACS), el más importante de esta área científica de la región, donde están indizadas 891 revistas de 26 países. Los artículos de nuestra revista están al día en este índice, cuyo acceso es http://lilacs.bvsalud.org/es/

Dentro de las redes sociales a las que pertenece la Asociación Colombiana de Radiología (ACR) se hacen publicaciones periódicas de los contenidos de la Revista Colombiana de Radiología. De esta manera, la Revista se hace visible en Facebook, Twitter, LinkedIn, Instagram y YouTube. En estas redes sociales tenemos seguidores y nos consultan por los enlaces los radiólogos asociados y no asociados de Colombia, los tecnólogos de imágenes diagnósticas, médicos, enfermeras y profesionales de disciplinas afines. Por ejemplo, en 2018, las publicaciones con contenidos de la Revista Colombiana de Radiología fueron vistas en Facebook por un número que osciló entre

1.300 y 6.900 personas. Estos seguidores son principalmente de Bogotá y Medellín, donde se concentra aproximadamente el $50 \%$ de la audiencia; otro tanto corresponde a seguidores que residen en Argentina, México, Perú, Venezuela, Ecuador, Bolivia, España y Estados Unidos. El $85 \%$ consulta los contenidos en español y los otros - cuyo idioma es diferente, como inglés, portugués, italiano, francés, alemán y árabe - consultan nuestros contenidos en inglés.

Las personas que siguen las publicaciones de la Revista en redes son de todas las edades, pero el grupo principal corresponde al rango entre 25 y 44 años. Se accede a estas publicaciones tanto por celular como por el computador, con una mayor tendencia al uso del celular como medio de consulta.

Las redes de la ACR donde se publican contenidos de la Revista son:

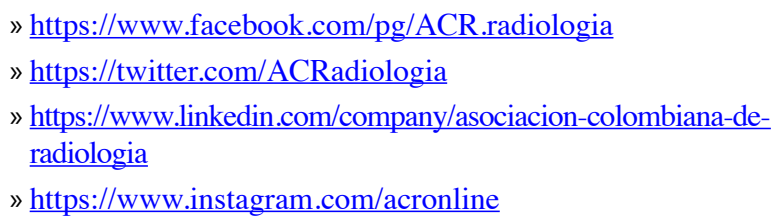

Al leer esta información, podemos sorprendernos con el cambio y la evolución que ha tenido la forma como nos comunicamos en los últimos años, y la Revista Colombiana de Radiología no se queda atrás en este cambio.

La invitación, entonces, es a seguir sus contenidos virtuales desde cualquier sitio y de la manera que les sea más familiar y cómoda y a compartir esta información con sus amigos, colegas radiólogos y de otras disciplinas, con sus alumnos, tecnólogos y enfermeras. El idioma no es un límite, dado que los contenidos se publican no solo en español, sino también en inglés. 